\title{
Orthodontics in SAARC Countries: Emerging the force within
}

\author{
Dr OP Kharbanda \\ Professor, Dept of Orthodontics, Centre for Dental Education \& Research \\ All India Institute of Medical Sciences, New Delhi, India
}

Orthodontics and Dentistry in SAARC countries have a unique evolutionary curve which seems to be having a strong linkage to its socio-cultural, economic and geopolitical rumination. The regional political and economical cooperation of the Indian subcontinent, the South Asian Association for Regional Cooperation (SAARC) was raised in 1980 and formally launched by seven countries by holding the First SAARC Summit in 1985. The seven countries included Bangladesh, Bhutan, India, Maldives, Nepal, Pakistan and Sri Lanka, which grew to eight full members with the late inclusion of Afghanistan in 2007. The SAARC region is home to a vast diversity of people, most of whom speak languages from the Indo-Aryan subgroup of the Indo-European family, Dravidians and Sino-Tibetans. Nearly $25 \%$ of the world population lives in this region, however emergence of Orthodontics was rather late in some of these member countries but emerged suddenly with quantum leap at the turn of the twentieth century. The First SAARC Orthodontic Conference was held in New Delhi in 2009.

The formal dental education in SAARC region was initiated with the founding of dental school in Calcutta in 1920 which offered one-year L.D.Sc. diploma. The first dental degree course in British India was established at De'Montmorency College of Dentistry in 1929 in Lahore. In Independent India, first dental faculty was established in 1957 at Mumbai subsequent to the formation of Dentists Act in 1948 and formation of Dental Council of India in 1949. East Pakistan; which is now Bangladesh saw its first formal dentistry course in 1961, Sri Lanka in 1943, and Nepal in 1998. In Afghanistan, Kabul Medical University now offers course in Stomatology or Dentistry since 2005. There is no dental college in Bhutan and Maldives so far.

The MDS courses in India including Orthodontia were established in 1959-1960 simultaneously at Nair Hospital Dental College and Government Dental College \& Hospital in Mumbai. In neighboring Pakistan; post-graduate fellowship (FCPS) was started under the aegis of College of Physicians and Surgeons (CPSP) in 1999, besides several universities also offer four years Masteral program in Orthodontics. Similarly in Bangladesh, first batch of post-graduate Orthodontics fellows were graduated in 2001 under Bangladesh College of Physicians and Surgeons (BCPS). A fiveyear MS residency program was initiated at Bangobandho Sheikh Mujib Medical University (BSMMU), Dhaka in 2006.

In Nepal, first PG orthodontic program (MDS Orthodontics) was started through National Academy of Medical Sciences-Bir Hospital in 2008. Later in 2010, Tribhuvan University started MDS (Orthodontics), B P Koirala Institute of Health Sciences, Dharan in 2012 and more recently, Kathmandu University started MDS (Orthodontics) in 2014. Sri Lanka offers MS Orthodontics program since 1989 at Postgraduate Institute of Medicine, University of Colombo. The PG Orthodontics program is now called MD in Orthodontics, which requires a fellowship certification.

India is perhaps one of the largest producers of Orthodontists with formal three years MDS program with nearly 700 enrollments per year in 186 post-graduate departments; while Nepal has 6-8 post-graduate seats in four institutions, and Sri Lanka with the intake of 2 seats or less per year in one institute. In Bangladesh two postgraduate departments offer nearly 25 Fellows per year while in Pakistan there are approximately 100 PG students in 21 CPSP accredited institutions and universities. In addition, many dental graduates from SAARC countries also pursue higher orthodontics education in China, Philippines, Russia, UK and USA.

There have been efforts of organizing the orthodontic profession in the subcontinent with the establishment of specialty professional orthodontic societies in various member countries. Indian Orthodontic Society (IOS) was established in 1965 and there are currently more than 1800 members. Bangladesh Orthodontic Society (BOS) was 
founded in 1993, now with 70 full members and 50 student members. Pakistan Association of Orthodontists (PAO) was established in 2006 with 71 life members and 150 student members, currently there are more than 100 qualified orthodontists in Pakistan. Orthodontic \& Dentofacial Orthopedic Association of Nepal (ODOAN) was established in 2007 with 30 life members, currently there are 80 qualified orthodontists in Nepal. Sri Lanka Orthodontic Society (SLOS) is specialty organization of qualified orthodontists, presently there are about 30 orthodontists in Sri Lanka.

Journal of Indian Orthodontic Society (JIOS) is the official publication of Indian Orthodontic Society, which was established in 1966. Pakistan Orthodontic Journal (POJ) is an official publication of the Pakistan Association of Orthodontists (PAO) started in 2009. Bangladesh Journal of Orthodontics \& Dentofacial Orthopedics (BJO\&DFO) is published since 2010 and Orthodontic Journal of Nepal (OJN) is published since 2011.

Traditionally, orthodontic training in India and subcontinent has been greatly influenced from North America and United Kingdom. In India and Pakistan first orthodontists were trained in USA. In Nepal and Sri Lanka first orthodontists were trained in UK. In Bangladesh early orthodontists were trained in UK and Japan. Indian clinicians and teachers trained in North America continued to teach Standard Edgewise Appliances; however, due to scarce availability of these materials, and later popularization of the concept of light forces, led them to consider other options like Begg's Appliance. Begg's appliance consequently established a strong and deeper position in this subcontinent in practice and teaching. During 80's, the Orthodontic fraternity in this region was influenced with functional appliances due to their proven clinical efficacy in growth modification. In 90's, the advent of pre-adjusted appliances led to a gradual drift and adaptation to these systems. Many practitioners moved to "Straight Wire Appliance" (SWA) while others adapted Tip Edge technique, a combination of Begg's appliance with the control of edgewise system. Lately Lingual orthodontics, Self-ligating bracket system and clear aligners are being propagated.

With my indulgence in SAARC countries through great mutual interactions, as Chairman of the first SAARC conference, and my several academic visits to Nepal and Bangladesh; I am witness and sensitive to orthodontics flavors of SAARC nations. Several issues pertaining to orthodontic practice in SAARC region needs a deeper look. The variety of ethnic groups has diverse craniofacial characteristics distinctive to each one of them. We the orthodontists practicing in this region need to consider and aim our treatment goals in lieu of the concept of 'beauty profile' and 'occlusion' to best optimize the result and suit the respective ethic group, and stop planning the treatment wearing glasses tainted with the norms of the west.

Further "quality assurance" seems to be a major concern which needs to be assured while these countries are taking leap in the 'number of orthodontists'. A major concern and awareness also needs promulgation about unwanted consequences of orthodontics and related procedures. The orthodontists are professionals who are susceptible to marketing by industry like any other humans. We, the orthodontists need to be up-to-date with global standards of care yet perform the best to suit the social, cultural, economic needs of the respective country. Patients' interest should occupy the top priority ever and always.

\section{OJN}

\section{REFERENCES}

1. SAARC Dhaka Declaration. https://www.saarc-sec.org/userfiles/ 01-Dhaka-1st Summit1985.pdf.

2. SAARC. Declaration of the fourteenth SAARC summit. http://www.saarc-sec.org/userfiles/Summit\%20Declarations/14\%20\%20New\%20 Delhi,\%2014th\%20Summit\%203-4\%20April\%202007.pdf .

3. History of Dental Council of India: Souvenir released on the occasion of Silver Jubilee of DCI 1973. Page 59-67: 70-73.

4. Parikh NH, Modi AB. Fifty Years of Orthodontic Education in Proceedings of the 22nd Indian Orthodontic Conference and Golden Jubilee of Orthodontic Education in India, Indore, 1987.

5. Jayna P, Chauhan DN. Development of the Orthodontic specialty in India. Proceedings of the 23rd Indian Orthodontic Conference 1988.

6. Shrestha RM. Nepalese history of Orthodontics. Orthod J Nep 201 1; 1 (1): 10.

7. http://www.bcpsbd.org

8. www.dciindia.org.in

9. www.iosweb.net

10. www.odoan.org.np

11. http://cpsp.edu.pk

12. http://pao.org.pk

13. www.srilankaorthodonticsociety.com 